\title{
Prevalence of self-reported coronary heart disease and its associated risk factors in Tabari cohort population
}

\author{
Ali Ghaemian ${ }^{1}$, Maryam Nabati ${ }^{1}$, Majid Saeedi ${ }^{2}$, Motahareh Kheradmand ${ }^{3}$ and Mahmood Moosazadeh ${ }^{3 *}$ (D)
}

\begin{abstract}
Background: Prevalence of coronary heart disease (CHD) risk factors are increasing in developing countries. The present study aimed to assess the prevalence of self-reported CHD and evaluate the role of various risk factors on its prevalence in the Tabari cohort study (TCS) population.

Methods: The enrollment phase of TCS was performed between June 2015 and November 2017. In the current study, data were derived from information collecting from the enrollment phase of TCS. In the enrollment phase, 10,255 individuals aged 35-70 living in urban and mountainous areas of Sari (northern part of Iran) were entered into the study. Educational level, socioeconomic and marital status, history of smoking, opium and alcohol abuse/ addiction, level of daily physical activity, indices of obesity, and traditional risk factors of the participants were determined.

Results: The prevalence of CHD was measured at 9.2\%. Older individuals $(P<0.001)$, people with a body mass index $\geq 30 \mathrm{~kg} / \mathrm{m} 2(P<0.001)$, diabetics $(P<0.001)$, and hypertensive $(P<0.001)$ have been shown to have an increased risk for CHD compared with participants of without CHD. Furthermore, the CHD was more prevalent in individuals with higher waist circumference $(P<0.001)$, higher low-density lipoprotein cholesterol $(P<0.001)$, lower high-density lipoprotein cholesterol $(P<0.001)$, and a higher waist to hip ratio $(P<0.001)$. In addition, individuals with low socioeconomic status, illiterate people, and opium users had a higher prevalence of $\mathrm{CHD}(P<0.001)$. The results of the multivariable logistic regression analysis showed that the probability of CHD among individuals who had 8-10 risk factors was estimated at 8.41 (95\% confidence interval: 5.75-12.31) times higher than those with less than 3 risk factors.
\end{abstract}

Conclusion: According to the results of the present study, it seems that the prevalence of CHD in the Iranian population is relatively high.

Keywords: Cardiovascular disease, Low and middle-income countries, Risk factors, Prevalence

\footnotetext{
* Correspondence: mmoosazadeh1351@gmail.com

${ }^{3}$ Health Science Research Center, Addiction Institute, Mazandaran University of Medical Sciences, Sari, Iran

Full list of author information is available at the end of the article
}

(C) The Author(s). 2020 Open Access This article is licensed under a Creative Commons Attribution 4.0 International License, which permits use, sharing, adaptation, distribution and reproduction in any medium or format, as long as you give appropriate credit to the original author(s) and the source, provide a link to the Creative Commons licence, and indicate if changes were made. The images or other third party material in this article are included in the article's Creative Commons licence, unless indicated otherwise in a credit line to the material. If material is not included in the article's Creative Commons licence and your intended use is not permitted by statutory regulation or exceeds the permitted use, you will need to obtain permission directly from the copyright holder. To view a copy of this licence, visit http://creativecommons.org/licenses/by/4.0/ The Creative Commons Public Domain Dedication waiver (http://creativecommons.org/publicdomain/zero/1.0/) applies to the data made available in this article, unless otherwise stated in a credit line to the data. 


\section{Background}

Cardiovascular disease is the most common cause of mortality in the world and its prevalence is increasing in the developing countries [1]. In recent years, ageadjusted mortality rates of CHD in high-income countries have declined significantly in spite of the increased burden of CHD [2]. Furthermore, the majority of related deaths in these countries occur in retirement ages [3]. This decline in CHD mortality is closely related to both primary and secondary preventive strategies and sustaining health promotion programs [4]. However, in the middle- and low-income countries, CHD remains the main cause of death and the greatest source of disease burden. In these countries, a large proportion of related deaths occur during productive and active ages [5]. Several factors, such as genetic inheritance, social, environmental, and lifestyle-related physical activity can affect the CHD risk. Some of these risk factors, including cigarette smoking, unhealthy diet, physical inactivity, and alcohol use are modifiable [6]. On the other hand, prevalence of traditional risk factors for CHD, including diabetes mellitus (DM), cigarette smoking, physical inactivity, overweightness and obesity, hypertension (HTN), and hyperlipidemia (HLP) are increasing in developing countries [7]. In the present study, data from the Tabari cohort were analyzed to determine the prevalence of self-reported CHD and evaluate the role of different anthropometric, behavioral, and traditional risk factors on the prevalence of self-reported CHD in northern part of Iran.

\section{Methods}

In the current study, data were derived from information collected in the enrollment phase of TCS population, which is a part of national cohort studies named the Prospective Epidemiological Research Studies in Iran (PERSIAN). The participants of TCS have been selected from areas of northern part of Iran (Sari city, Mazandaran province). Inclusion criteria included persons in the age group of 35-70 years, persons only officially resident and Iranian nationality. Exclusion criteria of the study included persons who did not unwillingness to participate in TCS for any reason, and persons who were not able to communicate, inability to speak, deafness and having acute mental disorders. The enrollment phase of TCS was performed between June 2015 and November 2017. We have enrolled 10255 participants aged 35-70 years in TCS. Among them 68.4\% lived in urban area and $40.5 \%$ of them were men. The questionnaire used for the data collection was a standardized questionnaire which has been explained in detail in methodology and cohort profiling studies $[8,9]$. Data regarding educational level, socioeconomic and marital status, history of cigarette or hookah smoking, drug and alcohol abuse/addiction, and level of daily physical activity were collected by a face to face interview. The absolute physical activity intensities were expressed in metabolic equivalents (METs). One MET was defined as $1 \mathrm{kcal} / \mathrm{kg} / \mathrm{h}$. Based on calculated METs, the intensity of physical activity was divided into four levels within $24 \mathrm{~h}$ : sedentary, low, medium, and high activities. Socioeconomic status was broken into five levels on the basis of 13 variables [6, 8, 9]. Anthropometric measurements were determined by trained personnel, in accordance with standard protocol [10]. According to WHO classification, individuals were categorized into two groups: with a healthy WHR $(0.9$ or less and 0.85 or less in men and women, respectively), and with a high-risk WHR ( 0.91 or higher in men and 0.86 or higher in women). The waist to height ratio (WHtR) was calculated by dividing waist circumference by height. Patients were then categorized into two groups: non-obese with a WHtR< 0.5 and obese patients with a WHtR $>0.5$ [11]. Also, blood pressure and laboratory data such as fasting blood glucose (FBS), total cholesterol and, HDL cholesterol were measured in TCS. The HTN was defined as having a systolic blood pressure $\geq 140 \mathrm{mmHg}$, diastolic blood pressure $\geq 90 \mathrm{mmHg}$, or requiring antihypertensive medications [12]. The DM was defined according to the guidelines of the American Diabetes Association (FBS $\geq 126 \mathrm{mg} / \mathrm{dl}$ ) or consuming oral hypoglycemic agents or insulin [13]. The HLP was characterized by a serum total cholesterol (TC) level <200mg/dl, high-density lipoprotein-cholesterol (HDL-C) level less than 40mg/dl in men, or less than $50 \mathrm{mg} / \mathrm{dl}$ in women [14]. Based on the literature, patients with a low-density lipoproteincholesterol (LDL-C) level $\geq 130 \mathrm{mg} / \mathrm{dl}$ are at risk for future adverse cardiovascular events [15]. Therefore, we divided the patients into two groups according to serum LDL-C: a group with LDL-C levels $<130 \mathrm{mg} / \mathrm{dl}$ and those with levels $\geq 130 \mathrm{mg} / \mathrm{dl}$. Hypertriglyceridemia was defined as a plasma triglyceride (TG) level of $\geq 150 \mathrm{mg} / \mathrm{dl}$ [16].

In Tabari cohort, individuals were considered to have CHD if they had one or more of the following factors: history of stable angina pectoris, unstable angina, prior myocardial infarction, heart failure, percutaneous coronary intervention or coronary artery bypass graft surgery. Two trained nurses were in charge of obtaining detailed medical history including CHD from each participant. The question was "have you ever been diagnosed for CHD by a physician?". If the answer was "Yes", all the medical records of the patients were reviewed by the physicians. Ten variables were regarded as risk factors for CHD. These include: TG $\geq 150 \mathrm{mg} / \mathrm{dl}, \mathrm{TC} \geq 200 \mathrm{mg} / \mathrm{dl}$, LDL-C $\geq 130 \mathrm{mg} / \mathrm{dl}$, and HDL-C $<50 \mathrm{mg} / \mathrm{dl}$ in women and $<40 \mathrm{mg} / \mathrm{dl}$ in men, $\mathrm{BMI} \geq 30 \mathrm{~kg} / \mathrm{m} 2$, less than moderate physical activity, WHR $>0.9$ for men and $>0.85$ for women, WHtR $\geq 0.5, \mathrm{DM}$, and HTN. It should be noted, 
family history of CHD in first and second degree of relatives was available, but it was not included in the analyses due to possible dilution of the association.

\section{Statistical analysis}

Continuous variables were expressed by mean and categorical variables by frequency and percentile. Patients were categorized into two groups based on having or not having self-reported CHD. An independent t-test was used to compare the means between the two groups. Categorical variables were compared by Chi-square. Furthermore, a multivariable logistic regression analysis was used to adjust the confounding effects of other variables on the prevalence of CHD. A $p$-value of less than 0.05 was considered statistically significant. We used SPSS 16 for analyzing the data of study (SPSS Inc., Chicago, Illinois, USA).

\section{Results}

According to the results of the enrollment phase of TCS, prevalence of CHD was calculated at 9.2\% (946/10, 255 individuals, confidence interval (CI) 95\%:8.7-9.8). The mean age of CHD patients was 51.24 \pm 9.45 years. Disease onset was at the age of less than 46, between 4657 , and more than 57 years in $25 \%, 50 \%$, and $25 \%$ of CHD patients, respectively. The age of the disease onset showed no significant difference between men and women $(51.78 \pm 9.56$ vs. $50.87 \pm 9.36, P=0.146)$. As it is presented in Fig. 1, in urban population the prevalence of self-reported CHD did not show any difference between men and women. Among the population living in rural regions, the prevalence of CHD was higher in men than women ( $4.8 \%$ vs. $1.3 \%$, respectively) and in participants younger than 40 years. However, its prevalence was higher in women than men in other age groups.

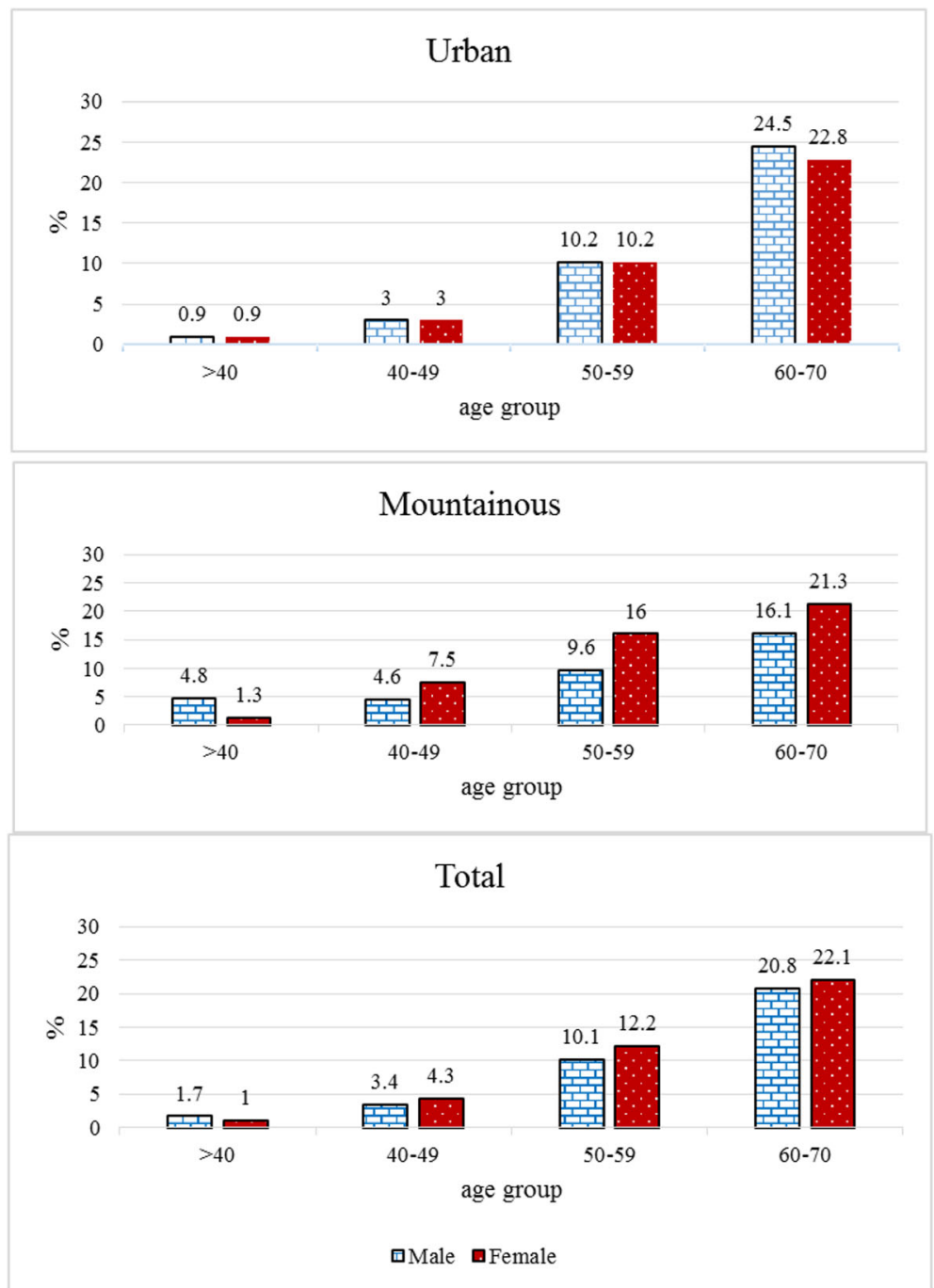

Fig. 1 Prevalenc of CHD categorized by age groups (years), sex and area of residence based on data of the enrollment phase of Tabari cohort study from Iran 
Table 1 Demographic and anthropometric variables of the study population categorized by having or not having self-reported CHD in men and women aged 35-70 years of Tabari cohort study enrolment phase from Iran

\begin{tabular}{|c|c|c|c|c|}
\hline \multirow[t]{2}{*}{ Variables } & & \multirow{2}{*}{$\begin{array}{l}N=946 \\
\text { With CHD; n (\%) }\end{array}$} & \multirow{2}{*}{$\begin{array}{l}N=9309 \\
\text { Without CHD; n (\%) }\end{array}$} & \multirow[t]{2}{*}{$P$-value (chi square test) } \\
\hline & & & & \\
\hline \multirow[t]{2}{*}{ Gender } & Male & $382(9.2)$ & $3767(90.8)$ & 0.959 \\
\hline & Female & $564(9.2)$ & $5542(90.8)$ & \\
\hline \multirow[t]{4}{*}{ Age (years) } & $<40$ & $20(1.2)$ & 1592(98.8) & $<0.001$ \\
\hline & $40-49$ & 135(3.9) & $3296(96.1)$ & \\
\hline & $50-59$ & $365(11.3)$ & $2865(88.7)$ & \\
\hline & $60-70$ & $426(21.5)$ & $1556(78.5)$ & \\
\hline \multirow[t]{2}{*}{ Residency } & Urban & $555(7.9)$ & $6457(92.1)$ & $<0.001$ \\
\hline & Rural & $391(12.1)$ & 2852(87.9) & \\
\hline \multirow[t]{5}{*}{ Education level } & University/college & 155(6.5) & 2219(93.5) & $<0.001$ \\
\hline & 9-12 years education & $170(5.9)$ & $2726(94.1)$ & \\
\hline & 6-8 years education & 103(9.2) & 1018(90.8) & \\
\hline & $1-5$ years education & 256(11.0) & 2076(89.0) & \\
\hline & illiterate & $262(17.1)$ & $1270(82.9)$ & \\
\hline \multirow[t]{5}{*}{ Social economic } & 1 & $246(12.0)$ & 1805(88.0) & $<0.001$ \\
\hline & 2 & 223(10.9) & 1829(89.1) & \\
\hline & 3 & 184(9.0) & 1866(91.0) & \\
\hline & 4 & $140(6.8)$ & $1911(93.2)$ & \\
\hline & 5 & 153(7.5) & 1898(92.5) & \\
\hline \multirow[t]{2}{*}{ Marital state } & Married & $863(9.2)$ & $8557(90.8)$ & 0.456 \\
\hline & Single-widow-divorce & $83(9.9)$ & 752(90.1) & \\
\hline \multirow[t]{3}{*}{ BMI $\left(\mathrm{kg} / \mathrm{m}^{2}\right)$} & $<25$ & $181(7.3)$ & 2292(92.7) & $<0.001$ \\
\hline & $25-29.9$ & $381(8.8)$ & 3962(91.2) & \\
\hline & $\geq 30$ & $384(11.2)$ & 3055(88.8) & \\
\hline \multirow[t]{2}{*}{ Cigarette smoking } & No & $876(9.4)$ & 8450(90.6) & 0.062 \\
\hline & Yes & $70(7.5)$ & $859(92.5)$ & \\
\hline \multirow[t]{2}{*}{ Alcohol user } & No & $876(9.3)$ & $8573(90.7)$ & 0.581 \\
\hline & Yes & $70(8.7)$ & 736(91.3) & \\
\hline \multirow[t]{2}{*}{ Opium user } & No & $861(8.9)$ & 8770(91.1) & $<0.001$ \\
\hline & Yes & $85(13.6)$ & $539(86.4)$ & \\
\hline \multirow[t]{2}{*}{ Hookah user } & No & $906(9.4)$ & 8766(90.6) & 0.042 \\
\hline & Yes & $40(6.9)$ & $543(93.1)$ & \\
\hline \multirow[t]{4}{*}{ Physical activity } & Sedentary & $282(11.0)$ & $2276(89.0)$ & 0.003 \\
\hline & Mild intensity & $212(8.2)$ & 2360(91.8) & \\
\hline & Moderate intensity & $221(8.6)$ & 2341(91.4) & \\
\hline & Severe intensity & $231(9.0)$ & 2332(91.0) & \\
\hline \multirow[t]{2}{*}{ Diabetic } & No & $626(7.4)$ & 7864(92.6) & $<0.001$ \\
\hline & Yes & $320(18.1)$ & 1445(81.9) & \\
\hline \multirow[t]{2}{*}{ Hypertensive } & No & $470(5.9)$ & 7504(94.1) & $<0.001$ \\
\hline & Yes & $476(20.9)$ & 1805(79.1) & \\
\hline \multirow[t]{2}{*}{ WC (cm) } & men $<102$ and women $<88$ & $392(7.5)$ & $4837(92.5)$ & $<0.001$ \\
\hline & men $\geq 102$ and women $\geq 88$ & $554(11.0)$ & $4472(89.0)$ & \\
\hline WHtR & $<0.50$ & $67(4.8)$ & $1326(95.2)$ & $<0.001$ \\
\hline
\end{tabular}


Table 1 Demographic and anthropometric variables of the study population categorized by having or not having self-reported CHD in men and women aged 35-70 years of Tabari cohort study enrolment phase from Iran (Continued)

\begin{tabular}{|c|c|c|c|c|}
\hline \multirow[t]{2}{*}{ Variables } & & \multirow{2}{*}{$\begin{array}{l}N=946 \\
\text { With CHD; n (\%) }\end{array}$} & \multirow{2}{*}{$\begin{array}{l}\text { N=9309 } \\
\text { Without CHD; n (\%) }\end{array}$} & \multirow[t]{2}{*}{$P$-value (chi square test) } \\
\hline & & & & \\
\hline & $>=0.50$ & $879(9.9)$ & 7983(90.1\%) & \\
\hline \multirow[t]{2}{*}{$\mathrm{HDL}-\mathrm{C}(\mathrm{mg} / \mathrm{dl})$} & men $\geq 40$ and women $\geq 50$ & $575(8.5)$ & $6225(91.5)$ & $<0.001$ \\
\hline & men $<40$ and women $<50$ & $371(10.7)$ & 3084(89.3) & \\
\hline \multirow[t]{2}{*}{ LDL-C (mg/dl) } & $<130$ & $83(5.8)$ & $1357(94.2)$ & $<0.001$ \\
\hline & $\geq 130$ & $863(9.8)$ & $7952(90.2)$ & \\
\hline \multirow[t]{2}{*}{$\mathrm{TC}(\mathrm{mg} / \mathrm{dl})$} & $<200$ & $310(5.6)$ & $5221(94.4)$ & $<0.001$ \\
\hline & $\geq 200$ & $636(13.5)$ & $4088(86.5)$ & \\
\hline \multirow[t]{2}{*}{$\mathrm{TG}(\mathrm{mg} / \mathrm{dl})$} & $<150$ & $286(5.3)$ & $5069(94.7)$ & $<0.001$ \\
\hline & $\geq 150$ & $660(13.5)$ & $4240(86.5)$ & \\
\hline \multirow[t]{2}{*}{ WHR } & men $\leq 0.9$ and women $\leq 0.85$ & $177(5.5)$ & $3068(94.5)$ & $<0.001$ \\
\hline & men $>0.9$ and women $>0.85$ & $769(11.0)$ & $6241(89.0)$ & \\
\hline \multirow[t]{9}{*}{ Number of risk factors } & None & $1(1.2)$ & 80(98.8) & $<0.001$ \\
\hline & one & $13(3.2)$ & 399(96.8) & \\
\hline & two & 23(3) & 744(97) & \\
\hline & Three & $59(5.1)$ & $1106(94.9)$ & \\
\hline & four & $78(4.7)$ & 1592(95.3) & \\
\hline & five & $128(6.2)$ & 1936(93.8) & \\
\hline & Six & 204(10.7) & $1711(89.3)$ & \\
\hline & Seven & 205(16) & 1077(84) & \\
\hline & Eight -Ten & $235(26.1)$ & 664(73.9) & \\
\hline
\end{tabular}

CHD Coronary heart disease, WC Waist circumference, WHR Waist to hip ratio, WHtR Waist to height ratio, BMI Body mass index, HDL High-density lipoprotein cholesterol, LDL Low-density lipoprotein cholesterol, TC Total cholesterol, TG Triglyceride

The prevalence of different demographic and anthropometric variables are presented in Table 1. There was no difference in the prevalence of cardiovascular disease between men and women $(P=0.959)$. However, the CHD prevalence increased with age $(P<0.001)$. Prevalence of CHD in individuals with a $B M I \geq 30 \mathrm{~kg} / \mathrm{m} 2$ was higher than in those with a $\mathrm{BMI}<25 \mathrm{~kg} / \mathrm{m} 2(11.2 \%$ vs. $7.3 \%, P<0.001)$, in diabetics higher than in nondiabetics $(18.1 \%$ vs. $7.4 \%, P<0.001)$, and in hypertensives higher than normotensives $(20.9 \%$ vs. $5.9 \%, P<0.001)$. Furthermore, the CHD was more prevalent in individuals with a higher WC (11.0\% vs. $7.5 \%, P<0.001)$, lower HDL-C $(10.7 \%$ vs. $8.5 \%, P<0.001)$, higher LDL-C $(9.8 \%$ vs. $5.8 \%, P<0.001)$, higher TC $(13.5 \%$ vs. $5.6 \%, P<0.001)$, and a higher WHR (11.5 vs. $5.5 \%, P<0.001)$. In addition, individuals with low socioeconomic status, illiterate people, and opium users had a higher prevalence of CHD $(P<0.001)$.

Multivariable logistic regression analysis showed that among different variables, older individuals aged 60-70 years had 10.51 times greater risk of having CHD than those aged 35-40 years, rural population 1.69 times than urban population, opium users 1.72 times than non-drug users, diabetics 1.28 times than non-diabetics, hypertensives 2.23 times than normotensives and individuals with a low HDL-C 1.51 times than those with high HDL-C. Moreover, individuals with intense physical activity were $37 \%$ less at risk of having CHD than those with a sedentary lifestyle (Table 2).

Table 3 represents the risk of developing CHD based on the number of individual's risk factors to adjust the effects of probable confounding variables which has been set according to the analysis from a hierarchical model. Model 1 evaluates the risk of developing CHD without adjusting the effects of other variables (crud model); model 2 describes the adjusted effect of gender; model 3 manifests the adjusted effect of age. In addition, model 4 demonstrates adjusted effects of socioeconomic status, level of education, marital status, area of residency, hookah or drug abuse, cigarette smoking, and alcohol consumption and model 5 shows adjusted effects of all included variables in models 2-4. All five models showed that the chance of having CHD increased significantly with increasing number of risk factors. Based on full model results (model 5), chance of having CHD in subjects with $3,4,5,6,7$, and 8-10 risk factors were 1.94, 
Table 2 Independent demographic and anthropometric Predictors of CHD according to multivariable logistic regression analysis in men and women aged 35-70 years of Tabari cohort study enrolment phase from Iran

\begin{tabular}{|c|c|c|c|c|}
\hline Variable & & OR & Cl 95\% & $P$-value \\
\hline \multirow[t]{2}{*}{ Gender } & Male & 1 & 1 & 1 \\
\hline & Female & 0.83 & $0.67-1.02$ & 0.077 \\
\hline \multirow[t]{4}{*}{ Age (years) } & $<40$ & - & - & - \\
\hline & $40-49$ & 2.47 & $1.53-4.00$ & $<0.001$ \\
\hline & $50-59$ & 5.86 & $3.67-9.37$ & $<0.001$ \\
\hline & $60-70$ & 10.51 & $6.51-16.97$ & $<0.001$ \\
\hline \multirow[t]{2}{*}{ Residency } & Urban & 1 & 1 & 1 \\
\hline & Rural & 1.69 & $1.36-2.10$ & $<0.001$ \\
\hline \multirow[t]{5}{*}{ Education level } & University/college & 1 & 1 & 1 \\
\hline & $9-12$ & 0.83 & $0.65-1.06$ & 0.127 \\
\hline & $6-8$ & 1.14 & $0.84-1.53$ & 0.403 \\
\hline & $1-5$ & 1.18 & $0.89-1.56$ & 0.230 \\
\hline & illiterate & 1.09 & $0.79-1.50$ & 0.613 \\
\hline \multirow[t]{5}{*}{ Social economic } & 1 & 1 & 1 & 1 \\
\hline & 2 & 1.07 & $0.86-1.33$ & 0.547 \\
\hline & 3 & 1.16 & $0.89-1.50$ & 0.256 \\
\hline & 4 & 1.08 & $0.81-1.45$ & 0.596 \\
\hline & 5 & 1.01 & $0.74-1.38$ & 0.934 \\
\hline \multirow[t]{2}{*}{ Marital state } & Single-widow-divorce & 1 & 1 & 1 \\
\hline & Married & 1.20 & $0.92-1.57$ & 0.177 \\
\hline \multirow[t]{3}{*}{ BMI $\left(\mathrm{kg} / \mathrm{m}^{2}\right)$} & $<25$ & 1 & 1 & 1 \\
\hline & $25-29.9$ & 0.93 & $0.73-1.19$ & 0.568 \\
\hline & $\geq 30$ & 1.07 & $0.81-1.42$ & 0.637 \\
\hline \multirow[t]{2}{*}{ Cigarette smoking } & No & 1 & 1 & 1 \\
\hline & Yes & 0.88 & $0.64-1.19$ & 0.400 \\
\hline \multirow[t]{2}{*}{ Alcohol user } & No & 1 & 1 & 1 \\
\hline & Yes & 1.04 & $0.76-1.42$ & 0.796 \\
\hline \multirow[t]{2}{*}{ Opium user } & No & 1 & 1 & 1 \\
\hline & Yes & 1.72 & $1.28-2.31$ & $<0.001$ \\
\hline \multirow[t]{2}{*}{ Hookah user } & No & 1 & 1 & 1 \\
\hline & Yes & 0.83 & $0.58-1.20$ & 0.327 \\
\hline \multirow[t]{4}{*}{ Physical activity } & sedentary & 1 & 1 & 1 \\
\hline & Mild intensity & 0.85 & $0.69-1.05$ & 0.134 \\
\hline & Moderate intensity & 0.81 & $0.66-1.00$ & 0.050 \\
\hline & Severe intensity & 0.63 & $0.49-0.80$ & $<0.001$ \\
\hline \multirow[t]{2}{*}{ Diabetic } & No & 1 & 1 & 1 \\
\hline & Yes & 1.28 & $1.08-1.51$ & 0.003 \\
\hline \multirow[t]{2}{*}{ Hypertensive } & No & 1 & 1 & 1 \\
\hline & Yes & 2.23 & $1.92-2.60$ & $<0.001$ \\
\hline \multirow[t]{2}{*}{ WC $(\mathrm{cm})$} & men $<102$ and women $<88$ & 1 & 1 & 1 \\
\hline & men $\geq 102$ and women $\geq 88$ & 0.98 & $0.78-1.23$ & 0.852 \\
\hline \multirow[t]{2}{*}{ HDL-C (mg/dl) } & men $\geq 40$ and women $\geq 50$ & 1 & 1 & 1 \\
\hline & men $<40$ and women $<50$ & 1.51 & $1.29-1.77$ & $<0.001$ \\
\hline
\end{tabular}


Table 2 Independent demographic and anthropometric Predictors of CHD according to multivariable logistic regression analysis in men and women aged 35-70 years of Tabari cohort study enrolment phase from Iran (Continued)

\begin{tabular}{|c|c|c|c|c|}
\hline Variable & & OR & Cl 95\% & $P$-value \\
\hline \multirow[t]{2}{*}{$\mathrm{LDL-C}(\mathrm{mg} / \mathrm{dl})$} & $<130$ & 1 & 1 & 1 \\
\hline & $\geq 130$ & 0.60 & $0.45-0.80$ & 0.001 \\
\hline \multirow[t]{2}{*}{$\mathrm{TC}(\mathrm{mg} / \mathrm{dl})$} & $<200$ & 1 & 1 & 1 \\
\hline & $\geq 200$ & 1.89 & $1.57-2.27$ & $<0.001$ \\
\hline \multirow[t]{2}{*}{$\mathrm{TG}(\mathrm{mg} / \mathrm{dl})$} & $<150$ & 1 & 1 & 1 \\
\hline & $\geq 150$ & 1.81 & $1.50-2.17$ & $<0.001$ \\
\hline \multirow[t]{2}{*}{ WHR } & men $\leq 0.9$ and women $\leq 0.85$ & 1 & 1 & 1 \\
\hline & men $>0.9$ and women $>0.85$ & 0.96 & $0.77-1.20$ & 0.740 \\
\hline \multirow[t]{2}{*}{$\mathrm{WHtR}$} & $<0.5$ & 1 & 1 & 1 \\
\hline & $>=0.5$ & 1.36 & $0.96-1.93$ & 0.085 \\
\hline
\end{tabular}

CHD Coronary heart disease, WC Waist circumference, WHR Waist to hip ratio, WHtR Waist to height ratio, BMI Body mass index, HDL High-density lipoprotein cholesterol, LDL Low-density lipoprotein cholesterol, TC Total cholesterol, TG Triglyceride

$1.62,2.02,3.37,4.91$, and 8.41 times higher $(95 \% \mathrm{CI})$, respectively, compared to those with less than 3 risk factors.

\section{Discussion}

According to the findings of the present study, the prevalence of self-reported CHD was measured at $9.2 \%$. We found no difference between the age of onset and prevalence of CHD between men and women. The CHD was more prevalent in older patients, people with a BMI $\geq 30 \mathrm{~kg} / \mathrm{m} 2$, diabetic, hypertensive, and individuals with a higher WC, WHR, LDL-C, TC, and a lower HDL-C. In addition, rural populations, individuals of lower socioeconomic status, illiterate people, and opium users had higher prevalence of CHD. Moreover, a greater number of $\mathrm{CHD}$ risk factors were associated with higher prevalence of self-reported CHD.

$\mathrm{CHD}$ is the most common cause of mortality in Iran. Prevalence of cardiovascular risk factors in Iran is increasing and almost half of all deaths per year and a high proportion (79\%) of deaths related to chronic illnesses are caused by CHD. Also, a large proportion of CHDrelated deaths occur during reproductive age. The impact of these events on health makes them as the most important health related problems in this country [5]. The prevalence of self-reported angina pectoris among Canadians aged 12 years old or older was reported about $5 \%$ and in the US adults aged 20 years or older was $6.9 \%$ [14]. More than $75 \%$ of all CHD-related deaths occur in developing countries. In India, the prevalence of CHD is 9-10\% among urban and 4-6\% in rural populations [15]. The prevalence of self-reported CHD in the current study was calculated at $9.2 \%$, which was relatively higher than other studies. This heterogeneity may be due to a complex interaction of various genetic and environmental factors that play an important role in the development of atherosclerosis. The prevalence of cardiometabolic risk factors (e.g., central obesity, hyperglycemia, HLP, and HTN) has been reported to be rising in recent years in Iran [17]. Moreover, in the present study only individuals aged 35 years or older were selected and younger people with a low probability of CHD were excluded from the study. In the current research, $75 \%$ of $\mathrm{CHD}$ patients reported that they developed this disease before the age of 57 , which is representative of a relatively early age of disease onset. Previous studies considered the age limit within 35-55 years for defining young coronary artery disease (CAD). The mean age of onset of CAD in Southeast Asians has been reported to be 53 years as compared to European age of 63 years. The incidence of CHD in younger persons is increasing over recent decades in developing countries [18]. This is consistent with findings of the present study.

Alizadeh Sani et al. used a data mining based approach for CAD diagnosis by arranging the features in four categories: demographic, symptoms and physical examination, electrocardiogram, and laboratory and echocardiographic findings. They found that the most important indicators for the detection of CAD patients were typical chest pain, age, HTN, DM, pulse rate, and BMI [19]. Aging, HTN, DM, physical inactivity, overweightness and obesity, and HLP are known as traditional risk factors for the development of atherosclerosis. The probability of developing CHD significantly rises if one or more of these risk factors exist [7]. BMI is an index of obesity that is associated with an increased risk of cardiovascular disease. However, recent studies have shown that the pattern of distribution of body fat is a more important determinant of risk than BMI [20]. Indeed, indices of abdominal obesity including WC, WHR, and WHtR have been linked with higher cardiometabolic risk [21]. In the present study, CHD was more prevalent among hypertensives, diabetics, and individuals with a 
Table 3 The relationship between various risk factors and CHD by number of risk factors according to multivariable logistic regression analysis in men and women aged 35-70 years of Tabari cohort study enrolment phase from Iran

\begin{tabular}{|c|c|c|c|c|}
\hline Model & Number of risk factors & OR & Cl 95\% & $P$-value \\
\hline \multirow[t]{7}{*}{ Model 1 (Crud) } & $0-2$ & 1 & 1 & 1 \\
\hline & 3 & 1.76 & $1.16-2.68$ & 0.008 \\
\hline & 4 & 1.62 & $1.09-2.41$ & 0.018 \\
\hline & 5 & 2.18 & $1.50-3.17$ & $<0.001$ \\
\hline & 6 & 3.94 & $2.76-5.64$ & $<0.001$ \\
\hline & 7 & 6.29 & 4.39-9.01 & $<0.001$ \\
\hline & $8-10$ & 11.69 & $8.17-16.76$ & $<0.001$ \\
\hline \multirow[t]{7}{*}{ Model 2 (Adjusted based on Gender) } & $0-2$ & 1 & 1 & 1 \\
\hline & 3 & 1.82 & $1.20-2.77$ & 0.005 \\
\hline & 4 & 1.69 & $1.13-2.52$ & 0.010 \\
\hline & 5 & 2.32 & $1.60-3.37$ & $<0.001$ \\
\hline & 6 & 4.24 & $2.96-6.07$ & $<0.001$ \\
\hline & 7 & 6.90 & $4.81-9.92$ & $<0.001$ \\
\hline & $8-10$ & 13.34 & $9.27-19.22$ & $<0.001$ \\
\hline \multirow[t]{7}{*}{ Model 3 (Adjusted based on age) } & $0-2$ & 1 & 1 & 1 \\
\hline & 3 & 1.78 & $1.16-2.72$ & 0.008 \\
\hline & 4 & 1.46 & $0.97-2.19$ & 0.066 \\
\hline & 5 & 1.78 & $1.22-2.59$ & 0.003 \\
\hline & 6 & 2.92 & $2.03-4.20$ & $<0.001$ \\
\hline & 7 & 4.21 & $2.92-6.08$ & $<0.001$ \\
\hline & $8-10$ & 7.18 & $4.97-10.36$ & $<0.001$ \\
\hline \multirow{7}{*}{$\begin{array}{l}\text { Model } 4 \text { (Adjusted based on social economic, } \\
\text { education level, area of residence, marital status, } \\
\text { cigarette smoking, hookah smoking, opium } \\
\text { addiction, use of alcohol) }\end{array}$} & $0-2$ & 1 & 1 & 1 \\
\hline & 3 & 1.84 & $1.20-2.79$ & 0.005 \\
\hline & 4 & 1.70 & $1.14-2.53$ & 0.010 \\
\hline & 5 & 2.20 & $1.51-3.21$ & $<0.001$ \\
\hline & 6 & 3.89 & $2.70-5.59$ & $<0.001$ \\
\hline & 7 & 5.95 & $4.12-8.58$ & $<0.001$ \\
\hline & $8-10$ & 10.59 & $7.33-15.30$ & $<0.001$ \\
\hline \multirow{7}{*}{$\begin{array}{l}\text { Model } 5 \text { (Adjusted based on age, gender, social } \\
\text { economic, education level, area of residence, } \\
\text { marital status, cigarette smoking, hookah } \\
\text { smoking, opium addiction, use of alcohol) }\end{array}$} & $0-2$ & 1 & 1 & 1 \\
\hline & 3 & 1.94 & $1.26-2.98$ & 0.003 \\
\hline & 4 & 1.62 & $1.08-2.44$ & 0.021 \\
\hline & 5 & 2.02 & $1.37-2.97$ & $<0.001$ \\
\hline & 6 & 3.37 & $2.32-4.89$ & $<0.001$ \\
\hline & 7 & 4.91 & $3.37-7.16$ & $<0.001$ \\
\hline & $8-10$ & 8.41 & $5.75-12.31$ & $<0.001$ \\
\hline
\end{tabular}

lower HDL-C and a higher LDL-C, TC, BMI, WC, and WHR.

Furthermore, it was more prevalent among illiterate and poor individuals than people of higher socioeconomic status. Lack of adequate access to health and social facilities causes people to become sicker and die earlier than people with a higher socioeconomic status. Awareness and education about risk factors of daily living activities may be partially responsible for a decrease in the CHD prevalence among individuals whit a high socioeconomic status [22]. Higher education is associated with better lifestyles and preventive measures, lower prevalence of risk factors, early detection and treatment of risk factors, better quality of acute coronary syndrome treatment, and better long-term management and compliance, compared to low education level [23].

In the present study, CHD was more prevalent in rural people than urban individuals. The altered epidemic 
pattern in rural regions, increased prevalence of cardiovascular risk factors, and an increase in the number of elderly people might explain these differences [24].

The prevalence of opium addiction has risen by three folds for the past 20 years in Iran and it is estimated that $2-2.8 \%$ of the population is addicted to opium which may be regarded as a risk factor for CHD. Opioids affect the hypothalamus by inhibiting the release of gonadotropin-releasing hormone, leading to reduction in the concentrations of plasma testosterone. There is a significant inverse correlation between plasma testosterone levels and the extent of CAD. Men with low testosterone levels might have an increased risk for coronary atherosclerosis. Testosterone may have some direct vasodilating effects on coronary vasculature. Consistent with the results of the present study, CHD was more prevalent in opium-addicted individuals than nonaddicted ones [25].

\section{Limitation}

We think that our study has some limitations. First in our study some patients might not have been aware of having CHD. This may lead to an underestimation of CHD prevalence in our population. Furthermore, the population of the present study was selected from individuals within the age range of $35-70$ years, who were living in the northern part of Iran. Therefore, the results of the present study cannot be generalized to the entire population of Iran. Finally, underestimation of the rate of opium and alcohol use could be another limitation of the present study. However, due to the close relationship between participants and the researchers we think that most patients answered honestly to this part of the questionnaire. On the other hand, the strength of our study is that it includes a large sample size which is more representative of the general population than smaller studies. We also evaluated the socioeconomic status of the population comprehensively

\section{Conclusion}

It seems that the prevalence of self-reported CHD in the Iranian population is relatively high, compared to other nations. In addition, the incidence of CHD in younger subjects is increasing. The rapid increase of CHD risk factors and sedentary lifestyle are the major determinants of a higher prevalence of CHD in this area. However, detrimental effects of inherited genetic risk factors on cardiovascular system should not be overlooked.

\section{Abbreviations}

CHD: Coronary heart disease; TCS: Tabari cohort study; DM: Diabetes mellitus; FBS: Fasting blood glucose; HTN: Hypertension; HLP: Hyperlipidemia; WC: Waist circumference; WHR: Waist to hip ratio; WHtR: Waist to height ratio; TC: Total cholesterol; HDL-C: High-density lipoprotein-cholesterol; LDLC: Low-density lipoprotein-cholesterol; TG: Triglyceride

\section{Acknowledgments}

We would like to thank all the members of PERSIAN cohort study (Ministry of Health and Medical Education and Mazandaran University of Medical Sciences) for all they did for PERSIAN cohort program.

\section{Authors' contributions}

AG and MM acquired data, performed the statistical analyses, interpreted data, and drafted and revised the manuscript for important intellectual content and approved the final version. MS and MK reviewed the analyses and the final version of the manuscript. MN interpreted data and revised the manuscript for important intellectual content and approved the final version. All authors have read and approved the manuscript.

\section{Funding}

TCS supported by the Ministry of Health and Medical Education (grant No. 700/534) and Mazandaran University of Medical Sciences (grant No. 2524). The funding body played no role in the design of the study and collection, analysis, and interpretation of data and in writing or decision to publish this manuscript.

\section{Availability of data and materials}

The datasets used and/or analysed during the current study are available from the corresponding author on reasonable request.

Ethics approval and consent to participate

This study was approved by Mazandaran University of Medical science ethical committee (IR.MAZUMS. REC.1395.2524). Written informed consent were obtained from all the participants.

\section{Consent for publication}

Not applicable.

\section{Competing interests}

The authors declare that there is no conflict of interest.

\section{Author details}

${ }^{1}$ Department of Cardiology, Faculty of Medicine, Cardiovascular Research Center, Mazandaran University of Medical Sciences, Sari, Iran. ²Department of Pharmaceutics, School of Pharmacy, Mazandaran University of Medical Sciences, Sari, Iran. ${ }^{3}$ Health Science Research Center, Addiction Institute, Mazandaran University of Medical Sciences, Sari, Iran.

Received: 6 February 2020 Accepted: 12 May 2020

Published online: 19 May 2020

\section{References}

1. Xu S, Jiayong Z, Li B, Zhu H, Chang H, Shi W, et al. Prevalence and clustering of cardiovascular disease risk factors among Tibetan adults in China: a population-based study. PLoS One. 2015;10(6):e0129966.

2. Joshi R, Jan S, Wu Y, MacMahon S. Global inequalities in access to cardiovascular health care: our greatest challenge. J Am College Cardiol. 2008:52(23):1817-25.

3. Gersh BJ, Sliwa K, Mayosi BM, Yusuf S. Novel therapeutic concepts the epidemic of cardiovascular disease in the developing world: global implications. Eur Heart J. 2010;31(6):642-8.

4. Gaziano TA. Reducing the growing burden of cardiovascular disease in the developing world. Health Aff. 2007;26(1):13-24.

5. Sadeghi M, Haghdoost AA, Bahrampour A, Dehghani M. Modeling the burden of cardiovascular diseases in Iran from 2005 to 2025: The impact of demographic changes. Iranian J Public Health. 2017;46(4):506.

6. Kheradmand M, Moosazadeh M, Saeedi M, Poustchi H, Eghtesad S, Esmaeili $\mathrm{R}$, et al. Tabari cohort profile and preliminary results in urban areas and mountainous regions of mazandaran, iran. Arch Iranian Med. 2019;22(6): 279-85

7. Yang Z-J, Liu J, Ge J-P, Chen L, Zhao Z-G, Yang W-Y. Prevalence of cardiovascular disease risk factor in the Chinese population: the 2007-2008 China National Diabetes and Metabolic Disorders Study. Eur Heart J. 2011; 33(2):213-20.

8. Poustchi H, Eghtesad S, Kamangar F, Etemadi A, Keshtkar A-A, Hekmatdoost A, et al. Prospective epidemiological research studies in Iran (the PERSIAN 
Cohort Study): rationale, objectives, and design. Am J Epidemiol. 2017; 187(4):647-55.

9. Eghtesad S, Mohammadi Z, Shayanrad A, Faramarzi E, Joukar F, Hamzeh B, et al. The PERSIAN cohort: providing the evidence needed for healthcare reform. Arch Iranian Med. 2017;20(11):691.

10. Klein S, Allison DB, Heymsfield SB, Kelley DE, Leibel RL, Nonas C, et al. Waist circumference and cardiometabolic risk: a consensus statement from shaping America's health: Association for Weight Management and Obesity Prevention; NAASO, the Obesity Society; the American Society for Nutrition; and the American Diabetes Association. Obesity. 2007;15(5):1061-7.

11. Garnett S, Baur L, Cowell C. Waist-to-height ratio: a simple option for determining excess central adiposity in young people. Int J Obes. 2008; 32(6):1028.

12. Chobanian AV, Bakris GL, Black HR, Cushman WC, Green LA, Izzo JL Jr, et al. Seventh report of the joint national committee on prevention, detection, evaluation, and treatment of high blood pressure. Hypertension. 2003;42(6):1206-52.

13. Association AD. Diagnosis and classification of diabetes mellitus. Diabet Care. 2008;31(Supplement 1):S55-60.

14. Wood D, De Backer G, Faergeman O, Graham I, Mancia G, Pyorala K. Prevention of coronary heart disease in clinical practice. summary of recommendations of the second joint task force of european and other societies on coronary prevention. J Hypertens. 1998;16(10):1407-14.

15. Ridker PM. LDL cholesterol: controversies and future therapeutic directions. Lancet. 2014;384(9943):607-17.

16. Beshara A, Cohen E, Goldberg E, Lilos P, Garty M, Krause I. Triglyceride levels and risk of type 2 diabetes mellitus: a longitudinal large study. J Invest Med. 2016;64(2):383-7.

17. Abbasi M, Neishaboury M, Koohpayehzadeh J, Etemad K, Meysamie A, Asgari F, et al. National prevalence of self-reported coronary heart disease and chronic stable angina pectoris: factor analysis of the underlying cardiometabolic risk factors in the surfncd-2011. Global Heart. 2018;13(2):73-82. e1.

18. Aggarwal A, Srivastava S, Velmurugan M. Newer perspectives of coronary artery disease in young. World J Cardiol. 2016;8(12):728.

19. Alizadehsani R, Habibi J, Hosseini MJ, Mashayekhi H, Boghrati R, Ghandeharioun A, et al. A data mining approach for diagnosis of coronary artery disease. Comp Methods Programs Biomed. 2013;111(1):52-61.

20. Mirmiran P, Esmaillzadeh A, Azizi F. Detection of cardiovascular risk factors by anthropometric measures in Tehranian adults: receiver operating characteristic (ROC) curve analysis. Eur J Clin Nutr. 2004;58(8):1110.

21. Ashwell M, Gunn P, Gibson S. Waist-to-height ratio is a better screening tool than waist circumference and BMI for adult cardiometabolic risk factors: systematic review and meta-analysis. Obes Rev. 2012;13(3):275-86.

22. Janati A, Matlabi H, Allahverdipour $\mathrm{H}$, Gholizadeh M, Abdollahi L. Socioeconomic status and coronary heart disease. Health Promot Perspect. 2011;1(2):105.

23. Pednekar MS, Gupta R, Gupta PC. Illiteracy, low educational status, and cardiovascular mortality in India. BMC Public Health. 2011;11(1):567.

24. He L, Tang X, Song Y, Li N, Li J, Zhang Z, et al. Prevalence of cardiovascular disease and risk factors in a rural district of Beijing, China: a populationbased survey of 58,308 residents. BMC Public Health. 2012;12(1):34.

25. Bafghi SS, Rafiei M, Bahadorzadeh L, Namayeh S, Soltani M, Andishmand MMA. Is opium addiction a risk factor for acute myocardial infarction? Acta Medica Iranica. 2005:4:218-22.

\section{Publisher's Note}

Springer Nature remains neutral with regard to jurisdictional claims in published maps and institutional affiliations.

Ready to submit your research? Choose BMC and benefit from:
- fast, convenient online submission
- thorough peer review by experienced researchers in your field
- rapid publication on acceptance
- support for research data, including large and complex data types
- gold Open Access which fosters wider collaboration and increased citations
- maximum visibility for your research: over 100M website views per year
At BMC, research is always in progress.
Learn more biomedcentral.com/submissions

